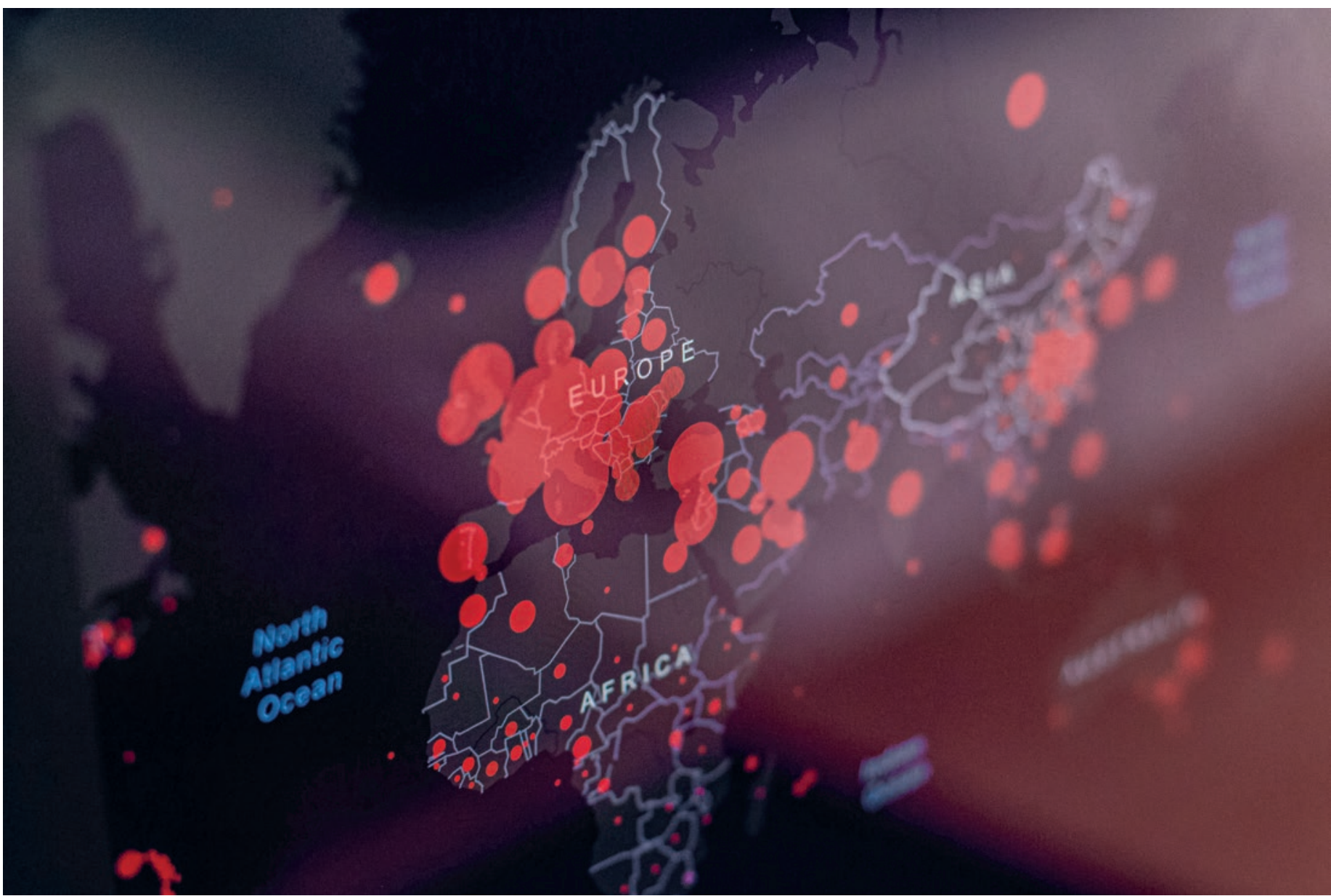

\title{
Die Varianten des Coronavirus noch gezielter verfolgen
}

\section{Redaktion der Schweizerischen Ärztezeitung}

Im Kampf gegen das Coronavirus richtet die Schweiz eine Überwachungsplattform ein, um neue Virusvarianten zu verfolgen. Die «Swiss Pathogen Surveillance Platform» erfasst die national gesammelten genetischen Sequenzen von COVID-19 zentral und gibt den Behörden einen Überblick über die Verteilung der Varianten im Land. Die Daten fliessen auch in internationale Datenbanken ein, die für die Erforschung des Virus genutzt werden.

Alpha, Delta und vielleicht bald Mu: Die Schweiz verfolgt das Entstehen neuer Varianten des Coronavirus und deren Übertragungsketten. Durch die Sequenzierung des Virusgenoms ist es heute möglich, die betreffende Variante und ihr vollständiges genetisches Profil anhand eines positiven PCR-Tests zu bestimmen. Bis August 2021 wurden mehr als 5600 Sequenzen von einem Dutzend akademischer und privater Labors in der ganzen Schweiz analysiert. Diese Daten sind jedoch nur dann von Nutzen, wenn sie schnell miteinander verknüpft werden können.

Um diesem Koordinationsbedarf gerecht zu werden, wurde eine nationale Überwachungsinfrastruktur geschaffen, die vom Schweizerischen Institut für 
Bioinformatik (SIB) co-geleitet wird, wie kürzlich in einer Pressemitteilung bekanntgegeben wurde. Die Swiss Pathogen Surveillance Platform (SPSP) zentralisiert, harmonisiert und kommentiert die genomischen SARS-CoV-2-Sequenzen aus den Schweizer Labors sowie die dazugehörigen Daten (Datum des PCR-Tests, Entnahmemethode, Grund für die Sequenzierung, verwendetes Gerät, Ort des Tests, Geschlecht und Alter der getesteten Person). Dieses neue Instrument unterstützt die nationale genomische Überwachungsstrategie unter der Leitung des Nationalen Referenzzentrums für neu auftretende Virusinfektionen (CRIVE) und des Bundesamts für Gesundheit (BAG) und bietet den Behörden einen umfassenden und automatisierten Überblick über die Sequenzierung in der Schweiz.

\section{Überwachung der Epidemie in Echtzeit}

Dreimal wöchentlich sendet die Plattform ihren genomischen Überwachungsbericht an das BAG, das ihn in seine Statistiken integriert. Die Informationen werden mit den Patientendaten abgeglichen, die über Krankenhausaufenthalte, Impfungen, Symptome zum Zeitpunkt der Untersuchung usw. vorhanden sind.

Mit dieser Strategie lässt sich feststellen, ob eine der beobachteten Mutationen mit einer höheren Pathogenität oder einer Impfstoffresistenz verbunden sein könnte. Aitana Lebrand, Team Lead Data Science am SIB und verantwortlich für die Plattform, erklärt: «Die

\section{Dreimal wöchentlich sendet die Plattform den genomischen Überwachungsbericht ans BAG, das ihn in seine Statistiken integriert.}

bisher eingegangenen Sequenzen stammen aus fast allen Schweizer Kantonen: Das ist eine hervorragende Nachricht. Das bedeutet, dass neue Varianten kaum eine Chance haben, unentdeckt zu bleiben.»

Die Plattform hilft zudem, wertvolle Zeit zu sparen. Das BAG erhält nicht mehr von jedem Labor Berichte in unterschiedlichen Formaten, sondern nur noch die Daten über die neue Plattform. Diese Zeitersparnis ermöglicht «einen höheren Detaillierungsgrad bei der Analyse von Sequenzierungsdaten. Dies ermöglicht es uns, unsere Bemühungen auf die Anpassung der öffentlichen Gesundheitspolitik zu konzentrieren", wird Mirjam Mäusezahl, Co-Direktorin der Sektion Epidemiologie des BAG, in der Pressemitteilung zitiert.

\section{Ein Schub für die internationale Forschung}

Die neue Plattform, die vom Staatssekretariat für Bildung, Forschung und Innovation (SBFI) finanziert

\section{Über die Schweizerische Überwachungs-} plattform für Krankheitserreger

Diese kollaborative Plattform folgt dem One-Health-Ansatz, das heisst, sie ist multidisziplinär und zielt unter anderem darauf $a b$, die Ergebnisse im Bereich der menschlichen Gesundheit zu optimieren. Die Plattform wird vom SIB in Zusammenarbeit mit den Universitätsspitälern Basel, Lausanne und Genf sowie den Universitäten Bern und Zürich betrieben. Sie wird auf der sicheren IT-Infrastruktur des SIB gehostet und entspricht den Datensicherheitsstandards des Swiss Personalised Health Network. Das SIB ist eine international anerkannte Non-Profit-Organisation, die sich auf biologische und biomedizinische Datenwissenschaften spezialisiert hat. Es vereint die Schweizer Bioinformatik-Community von rund 800 Forschenden und fördert die Zusammenarbeit und den Wissensaustausch.

wird, überträgt auch vollständig anonymisierte Virussequenzen an Plattformen für Open Science wie das europäische COVID-19-Portal, um die internationale Forschung zu fördern. Dank des Datenaustauschs ist die Schweiz heute nach dem Vereinigten Königreich, den USA und Deutschland einer der grössten Lieferanten von SARS-CoV-2-Sequenzen weltweit. Die öffentlich zugänglichen Datenbanken sind von entscheidender Bedeutung für die Untersuchung und das Verständnis der Bedeutung der beobachteten Variationen auf die Pathogenität des Virus, seine Interaktionen mit Wirtszellen zum Zeitpunkt der Infektion und für die Entwicklung von Impfstoffen und Behandlungen.

Für Christian Lovis, Direktor Medical Information Sciences am Universitätsspital Genf (HUG), «ist diese Initiative lobenswert und wird sicherlich nützlich sein, um sie in Zukunft auf andere Infektionserreger auszuweiten». Die Aufgabe der SIB-Plattform bestand ursprünglich darin, Fachleute zu unterstützen, das Auftreten und die Ausbreitung von Krankheitserregern rasch zu erkennen und frühzeitig Massnahmen zu ergreifen. Das Ziel war von Anfang an, Übertragungen einzudämmen, indem Erreger nahezu in Echtzeit verfolgt werden. Vor COVID-19 waren multiresistente Bakterien im Fokus. «Die Möglichkeit, SPSP langfristig zu nutzen, um genomische (Meta-)Daten über neu auftretende Bakterien oder Viren in der Schweiz mit epidemiologischen Daten zu verknüpfen, ist vielversprechend, um eine beispielhafte Reaktionsfähigkeit der Schweiz im Bereich der öffentlichen Gesundheit zu gewährleisten", so Mirjam Mäusezahl in der Mitteilung.

Quelle

SIB-Pressemitteilung. Die Schweiz richtet eine nationale Infrastruktur zur Verfolgung von COVID-19 und seinen Varianten ein. 13. Oktober 2021

Bildnachweis

KOBU Agency / Unsplash 